\title{
Constantes y tendencias métricas: el ritmo en Poe- mas (1958) de Carlos Germán Belli
}

\author{
Luis Eduardo Lino Salvador \\ Universidad Nacional Mayor de San Marcos \\ Universidad Antonio Ruiz de Montoya \\ luis.lino@unmsm.edu.pe
}

\begin{abstract}
Resumen
Se procede a realizar una primera revisión sobre las constantes y tendencias métricas del verso de Carlos Germán Belli en su primer libro publicado titulado Poemas (1958) desde el enfoque de los estudios de la versología. A partir de este análisis, se busca proponer un patrón métrico para este poemario y tratar de observar así la posibilidad de constituirse en la invariante del verso de Belli. Ello permitirá pensar en una poética del ritmo en sus versos basada en la relación tensa y dinámica existente entre las constantes y tendencias de los poemas estudiados.

Palabras claves: Carlos Germán Belli, metro, ritmo, poesía peruana.
\end{abstract}

\begin{abstract}
This article makes a first approach to the study of the constants and metric trends in the first book of Carlos Germán Belli: Poems (1958). The purpose is to propose an existing metrical pattern in that book and it can be thought of as a characteristic of his verses. It is also proposed the existence of a poetics based on the dynamic and tense relationship between the constants and metric trends studied rhythm poems.
\end{abstract}

Keywords: Carlos Germán Belli, metrics, rhythm, Peruvian poetry. 
Endecasílabos, heptasílabos, un cuasi soneto -noción propuesta por el propio poeta-, versos libres y el poema Canción al estilo Belli son parte del repertorio de formas métricas que ofrece el primer libro de Carlos Germán Belli titulado, sencillamente, Poemas (2008: 9-31) que data de 1958. La poesía de Belli es, sin duda, una cantera inagotable de estudio, análisis y reflexión tanto en los aspectos métrico-estróficos como en la dimensión semántica que se configuran en sus poemas. En este artículo, se seguirá la línea de investigación trazada por el profesor Elio Vélez Marquina en su artículo sobre Carlos Germán Belli que lleva por título "Símbolos y versos bellianos en "vamos rápido a tu reino»: nueva exégesis del Hada Cibernética” (2006: 93-105). En el mencionado trabajo, Vélez Marquina realiza un acercamiento al símbolo y a las tendencias y constantes métricas especialmente en el poema "Vamos rápido a tu reino" que forma parte del libro Acción de gracias (1992). El acercamiento sobre las constantes y tendencias lo lleva a cabo desde la perspectiva de la versología moderna desarrollada por el hispanista checo Oldrich Belic. Este punto me interesa en demasía, pues a partir de ello, mi propósito es realizar una inicial aproximación a las constantes y tendencias métricas desde la base metodológica de Belic, específicamente sobre el ya aludido primer poemario. Asimismo, se revisará el movimiento del ritmo organizado en sus poemas, ejercicio que posibilitaría pensar en la existencia de una poética del ritmo en sus versos. A todo ello es necesario agregar que no se dejará de apuntar algunas ideas sobre la relación dinámica y tensa entre el ritmo y la dimensión semántica de los poemas. Resulta oportuno desarrollar una revisión sobre este libro inaugural, pues permitirá observar cuáles fueron las características de los primeros poemas de Belli, de su pluralidad tanto temática como métrico-formal; así como también una posible base para realizar un estudio comparativo con su producción posterior1. Un estudio de las constantes y tendencias métricas conduce a realizar un análisis de interpretación acentual (Le Corre 1999: 134 y ss.) para luego identificar los tiempos marcados -sílaba métrica que recibe el acento de intensidad-, y describir su respectiva dispositio.

El poemario que se procede a revisar ofrece en su sintaxis dos partes. La primera se denomina "A la zaga" cuyas coordenadas temporales -según se consignan- van desde 1946 hasta 1951. La segunda parte se llama "Sin productos agrícolas" y el año referido es 1955 . Ambas partes dotan al poemario de una pluralidad temática y formal que puede constituirse en una las características de la obra de Carlos Germán Belli. Así, en la parte titulada "A la zaga" encontramos

1 En los últimos años, sobre nuestro poemario de estudio se puede contar con el trabajo de Camilo Fernández Cozman sobre el papel de la ironía como figura retórica desmitificadora (2008: 107-116). Allí, el crítico peruano parte del análisis del primer poema del libro que se va a revisar en estas líneas; así como también de un poema tanto de El pie sobre el cuello como de Dentro \& fuera. Ello lo realiza desde el marco teórico de la retórica general textual. 
en los cinco poemas el trabajo con versos endecasílabos, heptasílabos, el manejo del ritmo de timbre, del ritmo de tono2, de poemas monoestróficos y de la flexibilidad del ritmo de intensidad que es muy próximo al sistema prosódico denominado verso común variable o verso español típico (Belic 2000: 603-611). La segunda parte, "Sin productos agrícolas", está organizada a partir de nueve poemas y el primero es el único poema del conjunto que está conformado por cinco secciones y que responde al título "Variaciones para mi hermano Alfonso". El total de los poemas de "Sin productos agrícolas" ofrece el trabajo con diversas medidas silábicas que va desde el trisílabo hasta las más de veinte sílabas métricas3, un ritmo de timbre que emplea rimas con menor frecuencia para sorprender con el juego de las repeticiones de sonidos en el interior de los versos. También se trabaja con poemas poliestróficos entre ellos el denominado casi soneto con el que empieza el poema "Variaciones para mi hermano Alfonso" (Belli 2008: 21). En el plano de la temática de Poemas, David Sobrevilla plantea que este primer libro ofrecerá el repertorio de "estar postergado socialmente, la condición minusválida de su hermano Alfonso, el amor ideal e inalcanzable" (2006: 32) y que se pueden extender a la lírica posterior de Carlos Germán Belli 4.

El estudio de las constantes y tendencias métricas conduce a revisar en un primer momento dos de los poemas del libro que están construidos a partir de versos endecasílabos. El primero es el poema que es identificado gracias a su primer verso, a saber: "Nuestro amor no está en nuestro respectivos" y el segundo, también de la misma manera y cuyo primer verso dice "Si de tantos yo sólo hubiera angustia”. Obsérvese la interpretación acentual desarrollada sobre el primer poema:

2 Una muestra de dicho ritmo se manifiesta eficazmente con el juego de interrogaciones y exclamaciones que pueden observarse por ejemplo en los poemas, que pasamos a identificar con su primer verso, "¿Después de tanto pasaremos lares..." (Belli 2008: 14) y "Duro rigor de la pradera helada...” (Belli 2008: 15).

3 La presencia de dicho trisílabo se identifica en el poema que le da nombre a toda la segunda parte: "Sin productos agrícolas" (Belli 2008: 31) y los versos de más de veinte sílabas, en el poema "Las fórmulas" (Belli 2008: 27).

4 Preciso es también hacer referencia a la periodización que David Sobrevilla (2006: 29-36) elabora sobre la poesía de Belli. Propone dos periodos, a saber: "el del aprendizaje y el de la madurez poética" (31). El primero de ellos lo ubica desde 1943 hasta 1960 en el que, evidentemente, se inscribe el poemario que se comenta en este trabajo y el libro Dentro \& fuera. En este periodo, Sobrevilla detecta la coexistencia de una tradición clásica y de textos experimentales de influencia vanguardista. El segundo periodo, siguiendo a Roberto Paoli, Sobrevilla lo identifica como de "tendencia neoclásica" (32). Este periodo, asimismo, está conformado por dos etapas. La primera está marcada por "la búsqueda de un lenguaje con un vocabulario heteróclito" (32), vale decir, se trata de emplear palabras de diversos campos o esferas del saber. La segunda etapa está marcada por "una búsqueda de formas estróficas" (33), así como también del abandono del empleo del "vocabulario heteróclito" hacia un "léxico común y contemporáneo" (33). 


\section{Poema}

Nuestro amor no está en nuestros respectivos

$$
\begin{array}{lllllllllll}
\mathrm{x} & \mathrm{x} & \dot{\mathrm{X}} & \mathrm{x} & \dot{\mathrm{X}} & \dot{\mathrm{X}} & \mathrm{x} & \mathrm{x} & \mathrm{x} & \mathbf{x} & \mathrm{x}
\end{array}
$$

$\mathrm{y}$ castos genitales, nuestro amor

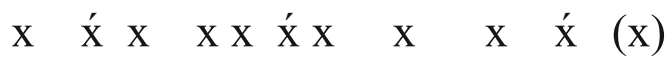

tampoco en nuestra boca, ni en las manos:

$\begin{array}{lllllllllll}\mathrm{x} & \dot{\mathrm{x}} & \mathrm{x} & \mathrm{x} & \mathrm{x} & \dot{\mathrm{x}} & \mathrm{x} & \mathrm{x} & \mathrm{x} & \dot{\mathrm{x}} & \mathrm{x}\end{array}$

todo nuestro amor guárdase con pálpito

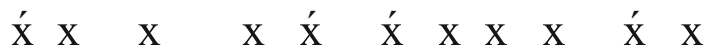

bajo la sangre pura de los ojos.

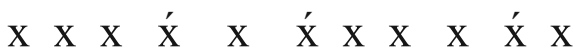

Mi amor, tu amor esperan que la muerte

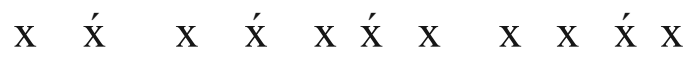

se robe los huesos, el diente y la uña,

$$
\begin{array}{lllllllllll}
\mathrm{x} & \mathbf{X} & \mathrm{x} & \mathrm{x} & \dot{\mathrm{X}} & \mathrm{x} & \mathrm{x} & \dot{\mathrm{X}} & \mathrm{x} & \dot{\mathrm{X}} & \mathrm{X}
\end{array}
$$

esperan que en el valle solamente

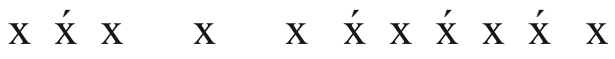

tus ojos y mis ojos queden juntos,

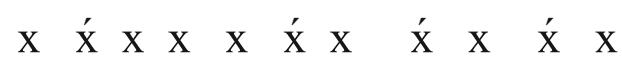

mirándose ya fuera de sus órbitas,

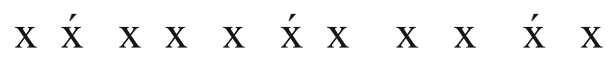

más bien como dos astros, como uno.

$$
\begin{array}{lllllllllllllllll}
\dot{x} & \dot{x} & \mathrm{x} & \mathrm{x} & \dot{\mathrm{x}} & \dot{\mathrm{x}} & \mathrm{x} & \mathrm{x} & \mathrm{x} & \dot{\mathrm{x}} & \mathrm{x}
\end{array}
$$

(2008: 13)

Dicha interpretación se puede sistematizar en el siguiente cuadro en el que se ofrece la distribución de los tiempos marcados y no marcados. Obsérvese a continuación: 


\section{Cuadro № 1}

Cantidad porcentual por cada sílaba métrica del texto "Poema"**

\begin{tabular}{|l|c|c|c|c|c|c|c|c|c|c|c|}
\hline Sílabas del verso & I & II & III & IV & V & VI & VII & VIII & IX & X & XI \\
\hline Número de acentos & 2 & 8 & 1 & 2 & 4 & 10 & 0 & 3 & 0 & 11 & 0 \\
\hline Porcentaje de acentos & 18 & 72 & 9 & 18 & 36 & 90 & 0 & 27 & 0 & 100 & 0 \\
\hline
\end{tabular}

* Se ha procedido a contabilizar solamente los tiempos marcados (acentos) y no marcados por cada sílaba métrica. Inmediatamente se ha calculado el número porcentual a partir de la siguiente fórmula: número de acentos de determinada sílaba multiplicado por el factor $100 \mathrm{y}$ dividido entre el número mayor de tiempos marcados que presente una de las sílabas.

Traduzcamos esta información estadística a hechos concretos. El análisis muestra que existe en total tres tiempos marcados que se convierten en constantes. Nos referimos a la segunda, sexta y, evidentemente, décima sílaba -esta última en su función de axis rítmico-, con un 72, 90 y 100\% de presencia de los tiempos marcados. Los golpes acentuales en dichas sílabas posibilitan proponer el trabajo con el endecasílabo heroico en este poema (Quilis 1989: 70). En el nivel de las tendencias, el conjunto de las sílabas impares poseen una menor presencia de los golpes acentuales o de los tiempos marcados. Así, la primera, tercera, séptima y novena sílabas métricas tienen 18,9 e incluso un $0 \%$ en dicho orden. De este conjunto hemos dejado de lado de manera deliberada una sílaba impar: la quinta sílaba; pues es la que posee un mayor número tiempos marcados y por extensión de porcentaje acentual (36\%). En el plano de las tendencias, esta quinta sílaba no solo es una mera excepción en la construcción del verso. Sobre todo constituye uno de los tiempos marcados más relevantes; ya que dinamiza, confronta y enriquece semánticamente al poema. Dinamiza, porque otorga flexibilidad y tiende a romper la posible rigidez de las constantes métricas. Confronta, pues, en tres versos ubicados estratégicamente en el poema, los tiempos marcados de dicha quinta sílaba y el correspondiente a una de las columnas acentuales del poema, vale decir, la sexta sílaba métrica, colisionan, chocan; haciendo valer ambos su condición de tiempos marcados y su valor semántico. Citamos como ejemplo de de ello, especialmente el cuarto verso: "todo nuestro amor guárdase con pálpito" (x́x xxx́ x́xx xx́x). Aquí se establece la relación del amor con el lugar en el cuál realmente se halla o se encuentra depositado (amor-guárdase), su acción y su modo; además, es importante notar cómo la presencia de la quinta sílaba define el primer golpe acentual de este mismo verso, el cual cae en la primera sílaba métrica5. El

5 Fenómeno que también se realiza en el último verso del poema. En dicho verso colisionan tanto la quinta con la sexta sílaba como la primera con la segunda. Es también el verso que más tiempos marcados posee y que, a la vez, sirve de cierre, desenlace y precisión al poema en su 
enriquecimiento semántico de esta quinta sílaba se produce incluso al convertirse en la sílaba columna del séptimo verso: "se robe los huesos, el diente y la uña," (xx́x xx́x xx́x x́x). En este verso el tiempo marcado de la sexta sílaba (constante en todo el poema) desaparece para ceder su lugar a la quinta sílaba. Este verso y la sílaba mencionada con su respectivo golpe acentual constituyen la enumeración de lo físico, del cuerpo y, por tanto, de lo perecedero ante lo que realmente queda, vale decir, el amor y la contemplación del mismo en la sinécdoque "ojos".

El segundo poema a revisar ("Si de tantos yo sólo hubiera angustia”) está organizado a partir de ocho versos endecasílabos. La interpretación acentual de dicho poema se ofrece a continuación:

Poema

Si de tantos yo sólo hubiera angustia, X x X́ x X́ X́ x X́ x X́ X

Yo solo frente a casas clausuradas, X́ X́ x X́ x X́ x x x X́ X

Sufrir por todos, flébil en los campos, $\mathrm{x}$ x́ x x́ x ́́ x x x x́ x

A la zaga del río, entre los tuertos. X X X́ X x X́ x X x X́ x

Si de mí sólo muerte se evadiera, X x X́ X́ x X́ X x x X́ x

Sólo yo me quedara insatisfecho, X́ x X́ x x x́ x x x X́ x

En medio de los parques cabizbajos, x X́ x x x X́ x x x X́ x

Solo yo, Adán postrero agonizando. X́ x X́ X́ x X́ x x x X́ x (2008: 16)

conjunto: la síntesis en la cual los amantes esperan y contemplan su amor capaz de ir más allá de la muerte. Cada golpe acentual refuerza semánticamente la estructura de este verso. 
Los tiempos marcados y no marcados del poema anterior con sus respectivas sílabas métricas y su porcentaje correspondiente pueden observarse en el siguiente cuadro:

\section{Cuadro № 2}

Cantidad porcentual por cada sílaba métrica del texto "Poema"*

\begin{tabular}{|l|c|c|c|c|c|c|c|c|c|c|c|}
\hline Sílabas del verso & I & II & III & IV & V & VI & VII & VIII & IX & X & XI \\
\hline Número de acentos & 3 & 3 & 5 & 4 & 1 & 8 & 0 & 1 & 0 & 8 & 0 \\
\hline Porcentaje de acentos & 37 & 37 & 62 & 50 & 12 & 100 & 0 & 12 & 0 & 100 & 0 \\
\hline
\end{tabular}

Se ha procedido a contabilizar solamente los tiempos marcados (acentos) y no marcados por cada sílaba métrica. Inmediatamente se ha calculado el número porcentual a partir de la siguiente fórmula: número de acentos de determinada sílaba multiplicado por el factor $100 \mathrm{y}$ dividido entre el número mayor de tiempos marcados que presente una de las sílabas.

Los datos estadísticos de este poema muestran que la sexta y décima sílabas métricas poseen la realización completa de todos los tiempos marcados con un $100 \%$ y la tercera realiza los tiempos marcados en un $62 \%$ lo que también permitiría pensar en su condición de constante para este poema. Entonces, la distribución de las constantes en sílabas tercera, sexta y su respectivo axis en la décima nos ofrecen un endecasílabo melódico (Quilis 1989: 70), que al ser comparado con el endecasílabo heroico del poema anterior nos muestra la flexibilidad y riqueza del verso de Belli, así como también el manejo de distintos endecasílabos que van acorde con la naturaleza temática abordada en sus poemas. Siguiendo con la lectura del cuadro estadístico, deseo centrarme en el tiempo marcado de la quinta sílaba que solo tiene un $12 \%$ de frecuencia de aparición y que del total de versos solo golpea en dicha sílaba una única vez. Es llamativo observar que el tiempo marcado en cuestión empieza en el primer verso y que es a la vez semánticamente relevante. Esa quinta sílaba del tiempo marcado del primer verso coincide con la aparición del sujeto del poema y a la vez su especificidad o singularidad. La aparición del Yo en ese verso y en un tiempo marcado de mínima frecuencia de aparición resulta medular en el poema de Belli, pues ocupará luego un lugar central en los otros versos al asumir la posición en sílabas que se convertirán luego en las constantes del poema. Me refiero específicamente a los versos cinco, seis y ocho en los que el Yo y sus variantes de la primera persona se instalan en la tercera sílaba de los versos aludidos recibiendo el respectivo golpe acentual. Mención del Yo del poema merece también el segundo verso y en especial su primera sílaba métrica. Es, como se aprecia, la segunda aparición del mencionado Yo y ocupa, en la sílaba del verso en cuestión, la calidad de tendencia. Es altamente significativo ello, 
pues si recordamos el primer verso, la aparición del yo también recae en una tendencia, vale decir, la quinta sílaba. Ello permite señalar que el poema presenta de manera inicial a su figura (el Yo del texto) más importante en sílabas de golpes acentuales que pertenecen a la tendencia métrica; ya que se trata de mostrar el leitmotiv en una progresión de menor a mayor. Ello queda justificado cuando se mencionó que el Yo y sus variantes pasan a ocupar lugares que le pertenecen a las constantes métricas. Es muy llamativo cómo en el texto de Belli se introduce al sujeto del poema desde lo menor (la tendencia) a lo mayor (la constante) y que a nivel de la dimensión semántica del poema el aludido Yo juegue un papel medular, relevante, en la construcción de su sentido.

Al lado de los versos endecasílabos, el primer poemario de Carlos Germán Belli trabaja también con versos heptasílabos. Por ejemplo, el poema de seis versos titulado "Las fórmulas mágicas" está organizado por las mencionadas medidas silábicas y obedece al siguiente orden de distribución: dos endecasílabos, dos heptasílabos y dos endecasílabos. Obsérvese el poema acompañado de su interpretación acentual:

Las fórmulas mágicas

Tienen el fino peso de la arena

X́ x x X́ x X́ x x x X́ x

las fórmulas mágicas que nos vienen

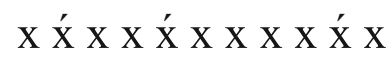

a través de los sueños:

$\mathrm{x}$ x X́ x x X́ x

transforman al amor

$\mathrm{x}$ X́ x x x x́ (x)

y me entregan una mujer fantasma,

x x x́ x x́ x x x́ x x́ x

la que cruza el puente y no llega a Lima.

$\mathrm{x}$ x x́ x x́ x x x́ x x́ x

(2008: 29)

Para visualizar con mayor claridad la disposición acentual de los versos heptasílabos y endecasílabos se ha procedido a presentarlos en dos cuadros sepa- 
rados. El propósito es notar que la construcción de este poema como unidad estrófica heterométrica (Quilis 1989: 94) se abre a un conjunto de posibilidades rítmicas y a la división en dos segmentos que ofrece el propio poema al trabajar con los dos puntos en su tercer verso. Véase los siguientes cuadros:

\section{Cuadro № 3}

Cantidad porcentual por cada sílaba métrica del verso heptasílabo del poema "Las fórmulas mágicas"*

\begin{tabular}{|l|c|c|c|c|c|c|c|}
\hline Sílabas del verso & I & II & III & IV & V & VI & VII \\
\hline Número de acentos & 0 & 1 & 1 & 0 & 0 & 2 & 0 \\
\hline Porcentaje de acentos & 0 & 50 & 50 & 0 & 0 & 100 & 0 \\
\hline
\end{tabular}

* Se ha procedido a contabilizar solamente los tiempos marcados (acentos) y no marcados por cada sílaba métrica. Inmediatamente se ha calculado el número porcentual a partir de la siguiente fórmula: número de acentos de determinada sílaba multiplicado por el factor $100 \mathrm{y}$ dividido entre el número mayor de tiempos marcados que presente una de las sílabas.

Es importante hacer notar que del cuadro anterior los versos heptasílabos no guardan regularidad en el golpe del tiempo marcado. Así, el tiempo marcado del primer heptasílabo golpea en la tercera sílaba y del segundo verso, en la segunda sílaba. Cada una de ellas cuenta con un solo golpe acentual. Esta información resulta medular si observamos los lugares en los cuáles golpean los acentos en los versos endecasílabos (ver cuadro $\mathrm{N}^{\circ} 4$ ). Con ello será posible observar cómo se integran en la unidad del poema ambos versos; así como también la manera como ambos construyen el movimiento rítmico del poema:

\section{Cuadro № 4}

Cantidad porcentual por cada sílaba métrica del verso endecasílabo del poema "Las fórmulas mágicas"*

\begin{tabular}{|l|c|c|c|c|c|c|c|c|c|c|c|}
\hline Sílabas del verso & I & II & III & IV & V & VI & VII & VIII & IX & X & XI \\
\hline Número de acentos & 1 & 1 & 2 & 1 & 3 & 1 & 0 & 2 & 0 & 4 & 0 \\
\hline Porcentaje de acentos & 25 & 25 & 50 & 25 & 75 & 25 & 0 & 50 & 0 & 100 & 0 \\
\hline
\end{tabular}

* Se ha procedido a contabilizar solamente los tiempos marcados (acentos) y no marcados por cada sílaba métrica. Inmediatamente se ha calculado el número porcentual a partir de la siguiente fórmula: número de acentos de determinada sílaba multiplicado por el factor $100 \mathrm{y}$ dividido entre el número mayor de tiempos marcados que presente una de las sílabas.

Si observamos las sílabas métricas dos y tres del cuadro $\mathrm{N}^{\circ} 4$, la cantidad de los tiempos marcados son de uno y dos. Al integrarlos con sus equivalen- 
tes de los versos heptasílabos se empezará a notar las proporciones que se establecerán entre las sílabas pares e impares. Si se hace la suma respectiva, tendríamos a la segunda sílaba con dos golpes acentuales y a la tercera con tres golpes acentuales. Si luego comparamos esta última cifra con la cantidad de la sílaba cinco del cuadro $\mathrm{N}^{\circ} 4$, entonces, sus cantidades son iguales. De la misma forma, el axis rítmico del cuadro $\mathrm{N}^{\circ} 3$ (sílaba seis) unido y sumado a la sexta sílaba del cuadro $\mathrm{N}^{\circ} 4$ nos entregan tres tiempos marcados. Llama la atención que en los endecasílabos solo exista un solo golpe acentual en la sexta sílaba, pues la constante de este verso es golpear en ella (Quilis 1989: 69-70). Los endecasílabos de este poema de Belli desplazan el golpe de la sexta sílaba a la quinta; sin embargo, en el poema como conjunto, los heptasílabos le devuelven su función relevante a aquella. El poema diseña de esta forma su movimiento rítmico que en el conjunto total marcharía así: tres, cinco, seis y diez. El poema logra construir su musicalidad no a partir de seguir la rigidez de una plantilla; sino a través de la flexibilidad de las posibilidades expresivas que le ofrecen tanto las palabras como la longitud de la medida silábica y sus potencialidades combinatorias.

El trabajo de Belli sobre el empleo de endecasílabos y heptasílabos en su primer libro también apunta al desarrollo del poema canción únicamente en tres textos6. El poema canción de Belli está conformado por una sola estrofa que posee en total catorce versos distribuidos a partir del siguiente orden: los primeros seis versos son endecasílabos, seguidos de tres heptasílabos, tres endecasílabos, un heptasílabo y un endecasílabo final. Si bien es cierto que la canción otorga libertad tanto en la disposición y tipo de rima (Quilis 1989: 143), en el caso de la canción de Belli, esta ofrece la siguientes disposición: 1) ABCBACcddEEFeF -la cual era empleada por Francisco de la Torre (Quilis 1989: 144), y 2) ABCABCcddEEFeF. En lo que corresponde a la distribución de los tiempos marcados es preciso remarcar la flexibilidad y libertad de ejecución de los mismos. La dinámica entre los tiempos marcados de los versos heptasílabos y endecasílabos opera con el complemento. Vale decir, en algunos poemas, el axis rítmico del verso heptasílabo posibilita que la sexta sílaba del verso endecasílabo pueda adquirir el rango de constante y convertirse en una de las columnas vertebrales del poema; incluso llega a superar al axis rítmico de los versos endecasílabos. Revisemos, a continuación, los tres poemas. Dos de ellos serán identificados por su primer verso, pues llevan como título el término ge-

6 Este poema canción vuelve a ser empleado en los poemas "No al desperfecto" de Oh hada cibernética (2008: 80), "Lo intempestivo" de Canciones y otros poemas (2008: 275-277) y en “¿Cuándo, señora mía?” de Bajo el sol de la medianoche rojo (2008: 393-395). Las rimas tienden a ser asonantes y con excepción del primer poema, los otros dos están conformados por varias estrofas de la misma estructura. 
neral "Poema”. Uno sí tiene un título propio, a saber, "La lisiada”. El orden que se propone es el siguiente7: primero el poema "Duro rigor de la pradera helada...", luego el texto "Después de tanto pasaremos lares...", (ambos poemas emplean el primer tipo de rima), y finalmente el poema "La lisiada" (segundo tipo de rima). Todos ellos son acompañados de su respectiva interpretación acentual y de su medida silábica:

\section{Poema}

Duro rigor de la pradera helada

X́ X X X́ X X X X́ X X́ X

que a vida mía toca y la destroza,

X X́ X X́ X X́ X X x X́ X

al alma hurtando en cada instante tierno

X X́ x X́ x X́ x X́ x X́ x

nuestro calor, iay!, nuestra lumbre hermosa.

X X X X́ X́ X X X́ X X́ X

¿Qué caminante con su yema alada

X́ X X X́ X X X X́ X X́ X

o qué mujer sutil tocará el cuerno

X X́ X X́ X X́ X X X́ X́ X

delante del invierno,

X X́ X X X X́ X

transfigurando todo

X X X X́ X X́ X

al más luciente modo?

X X́ X X́ X X́ X
(A) $11 \mathrm{SM}$

(B) $\quad 11 \mathrm{SM}$

(C) $\quad 11 \mathrm{SM}$

(B) $\quad 11 \mathrm{SM}$

(A) $11 \mathrm{SM}$

(C) $\quad 11 \mathrm{SM}$

(c) $\quad 7 \mathrm{SM}$

(d) $\quad 7 \mathrm{SM}$

(d) $\quad 7 \mathrm{SM}$

7 No se sigue el orden de aparición propuesto en el poemario el cual es "¿Después de tanto pasaremos lares...", "Duro rigor de la pradera helada..." y "La lisiada”. La razón obedece a criterios del análisis que se desea desarrollar en este trabajo. Pues, tal como se observará, el primer poema mencionado tienen en su cuarto y quinto verso diez y doce sílabas métricas respectivamente. Este hecho es altamente llamativo y significativo. En su momento se pretenderá ensayar una posible explicación. 
iOh la divina orden que al crudo atado

(E) $\quad 11 \mathrm{SM}$

$\mathrm{x}$ x x x́ x́ x x x́ x x́ x

rauda deshace por ser tan amado!,

(E) $\quad 11 \mathrm{SM}$

X́ x x X́ x x X́ x x X́ x

¿por qué no llega en esta noche fría,

(F) $\quad 11 \mathrm{SM}$

x X́ x X́ x X́ x X́ x X́ x

hasta este férreo prado,

(e) $7 \mathrm{SM}$

$\mathrm{x}$ X́ x X́ x X́ x

dándonos siquiera una alegría?

(F) $\quad 11 \mathrm{SM}$

X́ x x x x́ x x́ x x x́ x

(2008: 15) 8

\section{Poema}

¿Después de tanto pasaremos lares

(A) $\quad 11 \mathrm{SM}$

$\mathrm{x}$ x x x́ x x x x́ x x́ x

en que nos tocan el costado herido,

(B) $\quad 11 \mathrm{SM}$

$\mathrm{x}$ x x x́ x x x x́ x x́ $\mathrm{x}$

y a salvo todo bajo un dulce valle?

(C) $\quad 11 \mathrm{SM}$

$\mathrm{x}$ x́ x x́ x x x x́ x x́ x

¿Podremos ser el semblante ido

(B) $10 \mathrm{SM}$

$\mathrm{x}$ x́ x X́ x x x́ x X́ x

De los augustos faunos, ser en los mares

(A) $12 \mathrm{SM}$

x x x X́ x X́ x X́ x x x́ x

De nuevo sin que nadie nos acalle?

(C) $\quad 11 \mathrm{SM}$

x x́ x x x x́ x x x x́ x

¿Podremos el detalle

(c) $\quad 7 \mathrm{SM}$

x X́ x x x x́ x

8 En la interpretación acentual del penúltimo verso de este poema, se está considerando la presencia de una sinéresis en la palabra "férreo". Así, se construye una sílaba métrica en aquella que existen dos (Quilis 1989: 49). 
De las nubes divino,

(d) $\quad 7 \mathrm{SM}$

$\mathrm{x}$ x X́ x x X́ x

$\mathrm{O}$ el contorno del sino

(d) $\quad 7 \mathrm{SM}$

x x X́ x x x́ x

Pasarlos sin que voz airada llame

(E) $\quad 11 \mathrm{SM}$

x X́ x x x X́ x X́ x X́ x

Por entre viejo cierzo y nos reclame

(E) $\quad 11 \mathrm{SM}$

X x x X́ x X́ x x x X́ x

Ajena deuda y costras de mil llagas,

(F) $\quad 11 \mathrm{SM}$

$\mathrm{x}$ X́ x X́ x X́ x x X́ X́ x

Y lluvia no derrame,

(e) $7 \mathrm{SM}$

x X́ x x x X́ x

iay!, sobre nos, de fuegos y dagas?

(F) $\quad 11 \mathrm{SM}$

X́ x x X́ x X́ x x X́ x

(2008: 14)

La lisiada

Aquella cebra al lado de la niña

(A) $11 \mathrm{SM}$

x X́ x X́ x X́ x x x X́ x

lamiéndole su muslo mutilado,

(B) $\quad 11 \mathrm{SM}$

x x́ x x x x́ x x x x́ x

todo aquello al costado, tras el mundo,

(C) $\quad 11 \mathrm{SM}$

X́ x X́ x x X́ x X x X́ x

tras la gente adherida en una riña,

(A) $\quad 11 \mathrm{SM}$

$\mathrm{x}$ x X́ x x X́ x X́ x X́ x

todo aquello qué triste, qué fugado

(B) $\quad 11 \mathrm{SM}$

X́ x X́ x X́ X́ x X́ x X́ X

de la vera del mar, y qué profundo.

(C) $\quad 11 \mathrm{SM}$

x x X́ x x x́ x x́ x x́ x 


\begin{tabular}{|c|c|c|}
\hline Casto pie vagabundo & (c) & $7 \mathrm{SM}$ \\
\hline X́ x X́ x x X́ x & & \\
\hline de niña desprendido & (d) & $7 \mathrm{SM}$ \\
\hline \multicolumn{3}{|l|}{$\mathrm{x} \dot{\mathrm{X}} \mathrm{x} \times \mathrm{x} \dot{\mathrm{X}} \mathrm{x}$} \\
\hline para siempre y herido, & (d) & $7 \mathrm{SM}$ \\
\hline \multicolumn{3}{|l|}{ X X X́ X X X́ X } \\
\hline naufragando por bosques y arrabales, & (E) & $11 \mathrm{SM}$ \\
\hline \multicolumn{3}{|l|}{$\mathrm{x} x \dot{x} \mathrm{x} \times \dot{x} \mathrm{x} \times \mathrm{x} \dot{\mathrm{x}} \mathrm{x}$} \\
\hline delante de una cebra, entre fanales & (E) & $11 \mathrm{SM}$ \\
\hline \multicolumn{3}{|l|}{ X X́ x X́ x X́ x x x X́ X } \\
\hline de romeros, ioh niña!, ¿dónde el riente & $(\mathrm{F})$ & $11 \mathrm{SM}$ \\
\hline \multicolumn{3}{|l|}{ x x X́ x x X́ x x́ x x́ x } \\
\hline delfín, en qué canales & (e) & $7 \mathrm{SM}$ \\
\hline \multicolumn{3}{|l|}{ x X́ x X́ x x́ x } \\
\hline hoy en que no os abraza la corriente? & (F) & $11 \mathrm{SM}$ \\
\hline
\end{tabular}

(2008: 17)

Los tres poemas poseen ineludibles semejanzas. Una de ellas, sin duda, es el trabajo con la rima de naturaleza consonante que refuerza no solo la musicalidad de los versos, sino también la cohesión interna, la unidad, que existen entre ellos. Otra de las semejanzas se encuentra en el trabajo con el juego de las interrogaciones que existentes en estas canciones de Belli. No hay poema cuya organización corresponda con esta Canción en la que no se encuentre al menos una interrogante. Estas interrogantes no solo modifican el tono y tensan el movimiento rítmico del poema; también posibilitan establecer una función de contacto o de llamada dirigida al lector. Los poemas plantean las preguntas, pero no las resuelven; pues se sugiere el propósito de trasladarlas a la figura del lector y participar con ello en el desentrañamiento del sentido del poema.

Antes de proceder a realizar el examen sobre las constantes y las tendencias métricas resulta importante detenerse en la canción "Después de tanto pasaremos lares...". Dicho poema presenta en su cuarto y quinto verso medidas silábicas que escapan del conjunto endecasílabo. Así, el cuarto verso presenta 
diez sílabas y el quinto doce. Esta "fractura" del conjunto se ve enriquecida por el encabalgamiento que entre ellas se produce; a ello, como se muestra en dicho poema, hay que unir el encabalgamiento que también se produce entre el quinto verso (dodecasílabo) y el sexto (endecasílabo). Hecho que los cohesiona y configura su unidad. Además, a nivel semántico es necesario poner de relieve que son justamente estos versos que poseen medidas silábicas distintas, los que portan el único término que interroga sobre la posibilidad de las condiciones del Ser por las que podría optar el locutor del poema representado en la voz plural. Resulta, entonces, semánticamente llamativo que en medidas silábicas distintas del conjunto se deposite un término vinculado con la idea de la identidad del locutor y en el resto de versos endecasílabos las interrogantes traten sobre la posibilidad de su hacer. Revisemos el cuadro global de las constantes y tendencias que permitirá apreciar su valor en el conjunto9:

Cuadro № 5

Cantidad porcentual por cada sílaba métrica del verso endecasílabo del poema “¿Después de tanto pasaremos lares”"*

\begin{tabular}{|l|c|c|c|c|c|c|c|c|c|c|c|c|}
\hline Sílabas del verso & I & II & III & IV & V & VI & VII & VIII & IX & X & XI & XII \\
\hline Número de acentos & 1 & 8 & 2 & 8 & 0 & 10 & 1 & 5 & 2 & 8 & 1 & 0 \\
\hline Porcentaje de acentos & 10 & 80 & 20 & 80 & 0 & 100 & 10 & 50 & 20 & 80 & 10 & 0 \\
\hline
\end{tabular}

* Se ha procedido a contabilizar solamente los tiempos marcados (acentos) y no marcados por cada sílaba métrica. Inmediatamente se ha calculado el número porcentual a partir de la siguiente fórmula: número de acentos de determinada sílaba multiplicado por el factor $100 \mathrm{y}$ dividido entre el número mayor de tiempos marcados que presente una de las sílabas.

Los datos del cuadro $\mathrm{N}^{\circ} 5$ muestran que los golpes acentuales que se convierten en constantes son los que caen en las sílabas dos, cuatro, seis y diez pues alcanzan entre un ochenta y cien por ciento de frecuencia de realización; incluso se podría añadir a la sílaba ocho con su cincuenta por ciento. Los tiempos marcados de este poema canción al golpear en sílabas pares construyen la percepción de un ritmo de naturaleza yámbica. Piénsese también en los versos cuarto y quinto con su sintagma especial: "ser". En dichos versos tal término ocupa respectivamente la posición de las sílabas cuatro y ocho. Si observamos el cuadro, se podrá apreciar que también forman parte de las constantes del poema, por tanto, son golpes de medular relevancia para el mismo. Entonces,

9 A diferencia de los demás poemas que poseen dos medidas silábicas y, por tanto, se muestran dos cuadros; sobre este poema se procede a mostrar un único cuadro integral en el que se recogen todas las medidas silábicas que lo constituyen. Resulta más apropiado mostrarlo de esta forma, pues solo hablamos en el caso de decasílabo y el dodecasílabo de medidas que en el poema se caracterizan por ser de aparición única y no como un grupo. 
la medida silábica de los versos mencionados, la posición de las sílabas de su sintagma "ser" como constantes, hacen de estos elementos muy importantes en el poema canción de Belli.

Las canciones "Duro rigor de la pradera helada..." y "La lisiada" son poemas que a diferencia del anterior solo trabajan con heptasílabos y endecasílabos. En el plano de las constantes y tendencias métricas, los tres muestran notables similitudes en el diseño de su movimiento rítmico. Validemos esta afirmación, en primer lugar, con el análisis estadístico del poema "Duro rigor de la pradera helada..." a partir de los siguientes cuadros en los que se ha procedido a separar los heptasílabos y endecasílabos para una mayor comprensión:

\section{Cuadro № 6}

Cantidad porcentual por cada sílaba métrica del verso heptasílabo del poema "Duro rigor de la pradera helada..."*

\begin{tabular}{|c|c|c|c|c|c|c|c|}
\hline Sílabas del verso & I & II & III & IV & V & VI & VII \\
\hline Número de acentos & 0 & 3 & 0 & 3 & 0 & 4 & 0 \\
\hline Porcentaje de acentos & 0 & 75 & 0 & 75 & 0 & 100 & 0 \\
\hline
\end{tabular}

* Se ha procedido a contabilizar solamente los tiempos marcados (acentos) y no marcados por cada sílaba métrica. Inmediatamente se ha calculado el número porcentual a partir de la siguiente fórmula: número de acentos de determinada sílaba multiplicado por el factor $100 \mathrm{y}$ dividido entre el número mayor de tiempos marcados que presente una de las sílabas.

\section{Cuadro № 7}

Cantidad porcentual por cada sílaba métrica del verso endecasílabo del poema "Duro rigor de la pradera helada"*

\begin{tabular}{|l|c|c|c|c|c|c|c|c|c|c|c|}
\hline Sílabas del verso & I & II & III & IV & V & VI & VII & VIII & IX & X & XI \\
\hline Número de acentos & 4 & 4 & 0 & 9 & 3 & 4 & 2 & 6 & 1 & 10 & 0 \\
\hline Porcentaje de acentos & 40 & 40 & 0 & 90 & 30 & 40 & 20 & 60 & 10 & 100 & 0 \\
\hline
\end{tabular}

* Se ha procedido a contabilizar solamente los tiempos marcados (acentos) y no marcados por cada sílaba métrica. Inmediatamente se ha calculado el número porcentual a partir de la siguiente fórmula: número de acentos de determinada sílaba multiplicado por el factor $100 \mathrm{y}$ dividido entre el número mayor de tiempos marcados que presente una de las sílabas.

Del cuadro N. 6 las constantes caen sobre las silabas pares (dos, cuatro y seis) de manera contundente en el verso heptasílabo. Los tiempos marcados en el cuadro $\mathrm{N}^{\circ} 7$ muestran una mayor flexibilidad en la disposición de los mismos; sin embargo, los tiempos marcados pares tienden a sobresalir. En el conjunto del poema, dichos tiempos llegan a convertirse en constantes; así, la sílaba dos 
en la unidad del poema alcanza a tener un total de siete golpes acentuales. De la misma manera sucede con la sexta sílaba que en el total tiene ocho tiempos marcados. Un caso de suma importancia es el que ofrece la cuarta sílaba métrica que obtiene doce golpes acentuales. Al igual que en el poema anterior, este poema canción maneja como constantes métricas las sílabas dos, cuatro, seis y diez construyendo de esta forma un movimiento rítmico de naturaleza yámbica. Sin embargo, esta estructura yámbica se actualiza tensa y semánticamente gracias a los tiempos marcados que operan como tendencias y estas pertenecen a los versos endecasílabos. Si observamos el cuadro $\mathrm{N}^{\circ} 7$ sobre la sílaba uno recae cuatro tiempos marcados; sobre la cinco, tres y la sílaba siete apenas dos. En el poema estas tendencias juegan un papel relevante en el sentido y en la actualización del ritmo. Por ejemplo, el primer verso del poema empieza con un tiempo marcado. Su primera sílaba métrica posee un golpe acentual, hecho que desaparece en el siguiente verso, en el tercero y en el cuarto. Este último verso cierra este bloque con su pausa sintáctica fuerte, vale decir, con un punto y aparte. El quinto verso que abre un nuevo bloque de versos a partir del empleo de la interrogación, retoma el tiempo marcado en primera sílaba. Es decir, este tiempo marcado en primera sílaba (tendencia métrica) se encarga en abrir los bloques de versos. Se trata, entonces, de poner de relieve el inicio de cada uno de ellos golpeando en su primera sílaba. La función de esta tendencia a la vez es capaz de determinar la aparición de las otras tendencias. Por ejemplo, el verso "rauda deshace por ser tan amado!," tiene la siguiente secuencia de tiempos marcados 1- 4-7 - 10, que evidencia la aparición del golpe en sílaba siete con apenas un $20 \%$ de frecuencia de aparición. Aquí nuevamente aparece el sintagma "ser" esta vez sobre un tiempo marcado en función de tendencia y semánticamente relevante. Otro ejemplo de la importancia del tiempo marcado en la primera sílaba lo constituye el último verso del poema cuya secuencia de tiempos marcados es 1-5-7-10. Llama la atención que dicho verso cierre el conjunto con la presencia de tiempos marcados que operan en la función de tendencias. El último verso es, evidentemente, a nivel del sentido de suma importancia, pues pregunta sobre el deseo mínimo que invoca el locutor del poema. Tal pedido se ejecuta, pues, con los tiempos marcados de menor frecuencia del poema, vale decir, en las tendencias.

Resulta oportuno centrarse en el cuarto y décimo verso. En ambos se puede encontrar la colisión entre dos tiempos marcados inmediatos, vale decir, entre el golpe de la cuarta (constante) y la quinta sílaba (tendencia). Tomemos, por ejemplo, el cuarto verso. En dicho verso, el tiempo marcado de la constante (sílaba cuatro) posee al sintagma "calor" que en el sentido de los cuatro primeros versos constituye un bien sumamente valioso para el locutor del poema, para su propia vida. Dicho bien, sin embargo, se somete a la severidad de la "pra- 
dera helada”. Frente a ello, aparece el lamento, el dolor, la queja del locutor por aquello que se pierde, representada en el sintagma "iay!" acompañado de amplificadores semánticos y en el espacio de una sílaba (quinta) que pertenece a las tendencias. La pérdida del calor, el sufrimiento que produce ello, se pone de relieve en el poema en el encuentro inmediato de dos tiempos marcados que operan como constante y tendencia. El "calor" que se pierde, entonces, conduce al locutor al grito manifestado en ese "iay!" que se destaca y refuerza en el verso gracias a su disposición y golpe acentual.

En segundo lugar, observemos a continuación los dos cuadros siguientes en los que se propone la estadística de las constantes y tendencias métricas por cada medida silábica del poema "La lisiada":

Cuadro № 8

Cantidad porcentual por cada sílaba métrica del verso heptasílabo del poema "La lisiada"*

\begin{tabular}{|l|c|c|c|c|c|c|c|}
\hline Sílabas del verso & I & II & III & IV & V & VI & VII \\
\hline Número de acentos & 1 & 2 & 2 & 1 & 0 & 4 & 0 \\
\hline Porcentaje de acentos & 25 & 50 & 50 & 25 & 0 & 100 & 0 \\
\hline
\end{tabular}

* Se ha procedido a contabilizar solamente los tiempos marcados (acentos) y no marcados por cada sílaba métrica. Inmediatamente se ha calculado el número porcentual a partir de la siguiente fórmula: número de acentos de determinada sílaba multiplicado por el factor $100 \mathrm{y}$ dividido entre el número mayor de tiempos marcados que presente una de las sílabas.

\section{Cuadro № 9}

Cantidad porcentual por cada sílaba métrica del verso endecasílabo del poema "La lisiada"*

\begin{tabular}{|l|c|c|c|c|c|c|c|c|c|c|c|}
\hline Sílabas del verso & I & II & III & IV & V & VI & VII & VIII & IX & X & XI \\
\hline Número de acentos & 3 & 3 & 6 & 3 & 1 & 10 & 0 & 4 & 0 & 10 & 0 \\
\hline Porcentaje de acentos & 30 & 30 & 60 & 30 & 10 & 100 & 0 & 40 & 0 & 100 & 0 \\
\hline
\end{tabular}

* Se ha procedido a contabilizar solamente los tiempos marcados (acentos) y no marcados por cada sílaba métrica. Inmediatamente se ha calculado el número porcentual a partir de la siguiente fórmula: número de acentos de determinada sílaba multiplicado por el factor $100 \mathrm{y}$ dividido entre el número mayor de tiempos marcados que presente una de las sílabas.

El cuadro $\mathrm{N}^{\circ} 8$ ofrece una distribución acentual que involucra a las cuatro primeras sílabas métricas. Ello no significa que en cada uno de los versos se ejecuten todos los tiempos marcados en las sílabas aludidas. Significa que la 
estadística de este cuadro perfila un equilibrio entre los golpes acentuales. Las sílabas dos y tres poseen el mismo número de acentos al igual que las sílabas uno y cuatro. La flexibilidad de los heptasílabos que conforman este poema canción "La lisiada" se constituye en una característica fundamental. Observemos los primeros versos heptasílabos del mencionado poema que se ubican desde el verso séptimo al noveno. Encontramos que el primer golpe acentual de dichos heptasílabos se ubica en su conjunto de manera escalonada. Vale decir, en el primer heptasílabo (séptimo verso) el tiempo marcado se sitúa en la primera sílaba, en el segundo (verso octavo) el primer golpe acentual cae en la segunda sílaba y en el tercer heptasílabo (noveno verso) su primer tiempo marcado se ubica en la tercera sílaba. Dichos golpes acentuales y su escalonada disposición construyen un ritmo que los cohesiona y a ello hay que sumar el juego de encabalgamientos que enlaza a dichos versos, no interrumpido por pausa sintáctica alguna haciendo que el ritmo acentual resulte progresivo, reforzando aún más su unidad y cohesión.

Si la flexibilidad es una característica de los heptasílabos de este poema, esta también se extiende a la disposición acentual de los endecasílabos. El cuadro $\mathrm{N}^{\circ} 9$ presenta golpes acentuales en ocho de las once sílabas que conforman este verso, siendo las de mayor porcentaje la tres y la seis que se perfilan como las constantes. Al integrar ambas medidas silábicas en la unidad del poema se aprecia que las sílabas mencionadas (tres y seis) afirman su carácter de constantes con un total de ocho golpes acentuales en la sílaba tres y de catorce en la sílaba seis que a la vez es el número máximo de tiempos marcados que puede recibir una sílaba en este poema. A todo ello es necesario añadir la sílaba diez con diez golpes acentuales -evidentemente, este golpe acentual es el axis rítmico del verso endecasílabo. Las constantes para este poema, entonces, son los tiempos marcados en tres, seis y diez. A partir de ello, el ritmo del poema resulta ser de naturaleza melódica, si se sigue la distribución acentual global del mismo a la manera de los endecasílabos. En el plano de las tendencias, es necesario remarcar la aparición de un solo golpe acentual en la sílaba cinco del quinto verso. Este tiempo marcado se confronta con el golpe acentual de la sílaba seis de ese mismo verso y que sobre dicha posición se realizan todos los tiempos marcados dada su característica de constante. Nos encontramos, entonces, nuevamente ante la colisión de dos tiempos marcados en posiciones de tendencia y de constante10. Ello, sin duda, posee también una implicancia a nivel del sentido. Por ejemplo, los cuatro primeros versos del poema evidencian, a nivel del sentido, la condición física de la niña y a un animal capaz de

10 Este quinto verso es, además, de todo el poema el que más tiempos marcados posee. El resto oscila entre dos y cuatro tiempos marcados.

LETRAS 86 (123), 2015 
"consolarla" con su lamido frente a la situación nada pacífica de los demás. En otras palabras, la violencia, conflicto, que como señala el cuarto verso existe entre esa gente que al parecer no percibe el drama de la niña. Asimismo, dicho drama sucede en un espacio diferente al del mundo, al de la "gente" en pugna. Ese otro lugar que puede ser pensado como muestra de su indiferencia hacia lo que vive la niña. Este hecho en su complejidad despierta el lamento y el pesar del locutor en el "...qué triste..." del poema que se produce y destaca del choque entre dos tiempos marcados que, como ya se mencionó, trabajan como tendencia y constante respectivamente. Se trata, entonces, de resaltar la valoración del locutor del poema sobre esa muestra de indolencia de los otros frente a lo que padece la niña lisiada. El locutor muestra en la colisión de los tiempos marcados su estado de ánimo, su posición frente a la calamidad que padece la niña. Los golpes acentuales de las sílaba cinco y seis, además, se organizan y perciben diferentes de los versos anteriores: se fractura el movimiento rítmico de los versos precedentes para lograr con el encuentro de dos golpes acentuales consecutivos poner de relieve el “...qué triste..." del locutor. En otras palabras, remarcar rítmica y semánticamente su voz. Es a la vez importante que en ese quinto verso se vuelva a iterar la partícula "qué" y que se extienda también en el sexto verso. En ambos casos, sus golpes acentuales coinciden en la sílaba ocho de sus respectivos versos y a la luz del cuadro $\mathrm{N}^{\circ} 9$ ocupan la posición de tendencias métricas. Así, vemos que las tendencias juegan también un papel fundamental en la dinámica del sonido y del sentido de este poema.

Finalmente, los cuadros revisados de los poemas canciones de Belli operan como constantes generales con los golpes acentuales en las sílabas seis y diez que evidentemente revelan la estructuración de la medida silábica de los versos que lo conforman. Además, existen constantes particulares en sus canciones que recaen en las sílabas dos y cuatro; mientras que en el poema "La lisiada" su constante particular cae en la sílaba tres. La información que proporcionan los cuadros $\mathrm{N}^{\circ} 1,2,3,4$ al integrarla a los poemas canciones permiten obtener un patrón o metro del verso de Belli en su primer poemario. Así, las constantes generales nuevamente son los golpes en sílabas seis y diez; y las constantes específicas en sílabas dos, tres y cuatro. Si se procede a integrar esta información con aquella que detectó el profesor Vélez Marquina en su análisis del poema "Vamos rápido a tu reino", Acción de gracias (1992); entonces, se identificará que las constantes encontradas en esos versos se ubican en las constantes generales propuestas en su primer poemario, a saber: sílabas seis y diez. Este fenómeno que no solo debe ser visto como un rasgo de todo endecasílabo -medida silábica que en sí es también una constante métrica en Belli; sino también que a ello es necesario integrar las tendencias entendidas 
como su posibilidad de ejecución y realización en el cuerpo del poema, en otros términos, como su ritmo: actualización viva y dinámica de un metro. Puede pensarse, entonces, que ese patrón o metro se configuraría como una de las características invariantes del verso de Belli, esta es: dos, (tres), cuatro, seis y diez. Sin duda, esta afirmación puede resultar, a todas luces, audaz; sin embargo, para este primer poemario revisado y para el poema analizado por el profesor Vélez Marquina la afirmación resulta válida. Con ello no se trata de indicar que la estructura del verso de Belli es rígida. Por el contrario, tal cual se ha observado en todo este trabajo, la flexibilidad es también la invariante de su verso manifestada y operada en las ya mencionadas tendencias que dinamizan, tensionan y enriquecen semánticamente sus poemas.

La poética del ritmo en este primer poemario de Belli, a la luz del análisis de los estudios versológicos, se construye a partir del despliegue de tiempos marcados constantes, de la presencia de tendencias métricas que marcan incluso una ejecución distinta de la orquestada por las constantes y que también en algunos poemas las enfrentan al estar ubicados en la línea del verso de manera consecutiva. Todo ello enriquece rítmica y semánticamente sus poemas en una dialéctica dinámica y tensa.

La musicalidad en Poemas (1958) de Belli a partir de lo analizado no se construye en el simple impresionismo. Dicha musicalidad se perciben en la relación del material verbal objetivo (versos, propiedades prosódicas del idioma, sistema versal) que permiten la percepción subjetiva de los mismos en nuestra conciencia rítmica (Belic 2000: 513).

\section{Referencias bibliográficas}

BELIC, Oldrich (2000). Verso español y verso europeo. Una introducción a la teoría del verso español en el contexto europeo. Santafé de Bogotá: Instituto Caro y Cuervo.

BELLI, Carlos Germán (2008). Los versos juntos 1946-2008. Poesía completa. Sevilla: Sibila Fundación BBVA.

CORRE, Herve Le (1999). "Innovaciones y reticencias en torno al verso libre (con un ejemplo del posmodernismo cubano)”. En: Gema Areta Marigó, Hervé Le Corre, Modesta Suárez y Daniel Vives (eds.) Poesía hispanoamericana: ritmo(s)/ métrica(s)/ ruptura(s). Madrid: Editorial Verbum, pp. 111-143.

FERNÁNDEZ COZMAN, Camilo (2008). La poesía hispanoamericana y sus metáforas. Murcia: Universidad de Murcia.

QUILIS, Antonio (1989) [1984]. Métrica española. Edición corregida y aumentada. Barcelona: Editorial Ariel. 
SOBREVILLA, David (2006). "La poesía de Carlos Germán Belli: Una cumbre de la poesía peruana”. En: Miguel Ángel Zapata (ed.) Asir la forma que se va. Nuevos asedios a Carlos Germán Belli. Lima: Fondo Editorial UNMSM, pp. 29-36.

VÉLEZ MARQUINA, Elio (2006). "Símbolos y versos bellianos en «vamos rápido a tu reino»: nueva exégesis del Hada Cibernética". En: Miguel Ángel Zapata (ed.) Asir la forma que se va. Nuevos asedios a Carlos Germán Belli. Lima: Fondo Editorial UNMSM, pp. 93-105. 